\title{
Supplement to: The ICAD (Iterative Cavity Enhanced DOAS) Method
}

\author{
Martin Horbanski ${ }^{1,2}$, Denis Pöhler ${ }^{1,2}$, Johannes Lampel ${ }^{1,2}$, and Ulrich Platt ${ }^{1,2}$ \\ ${ }^{1}$ Institute of Environmental Physics, University of Heidelberg, Germany \\ ${ }^{2}$ Airyx GmbH, Justus-von-Liebig-Str. 14, 69214 Eppelheim, Germany
}

Correspondence: martin.horbanski@iup.uni-heidelberg.de

\section{S1 Comparison of Mobile Measurements to Air Quality Stations}

The temporal variation of the $\mathrm{NO}_{2}$ levels during the measurement cruise (from section 5.2) is further compared to the hourly $\mathrm{NO}_{2}$ levels measured by the air quality stations operated by the State Office for the Environment, Measurements and Nature Conservation of the Federal State of Baden-Württemberg (LUBW) ${ }^{1}$ (fig. S2). The hourly averages of the $\mathrm{ICAD} \mathrm{NO}_{2}$ measurements are similar to the LUBW stations. This indicates that the large scale average of the $\mathrm{NO}_{2}$ mixing ratio is well represented by the air quality network. However, on the local scale the ICAD time series shows a strong variability with peak values being almost four times higher than the hourly average. The peak levels of $\mathrm{NO}_{2}$ regularly exceed $105 \mathrm{ppb}$, the hourly EU limit value. Such peak values are especially found in street canyons where ventilation is limited and at intersections of big roads where cars frequently accelerate from a standstill position. This hints, that there are areas where we have $\mathrm{NO}_{2}$ levels are strongly underestimated by the average values from the monitoring stations, and therefore require a reassessment of the air quality. However, to make a certain statement on the air quality measurement drove from this pilot study would need to be repeated over a longer time period and also would need to revisit the same points at different times of day to reduce systematic errors induced by traffic pattern and meteorology.

\footnotetext{
${ }^{1}$ Data taken from the data and map service (UDO) of the LUBW. https://udo.lubw.baden-wuerttemberg.de Accessed 04-15-2018
} 


\section{S2 Figures}

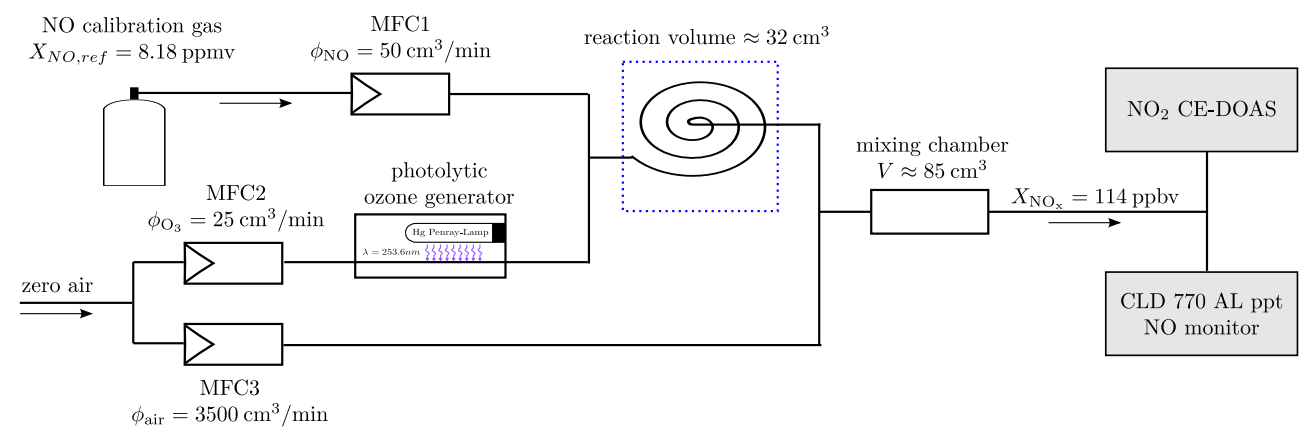

Figure S1. Measurement setup for the laboratory measurements. To produce $\mathrm{NO}_{2}, \mathrm{NO}$ from a calibration gas cylinder is titrated with $\mathrm{O}_{3}$, generated photolytically from zero air from a gas bottle. Two calibrated mass flow controllers (MFC1, MFC2) provide a constant gas flow. They are adjusted to ensure that the gas phase titration is completed to at least $99 \%$ after one third of the residence time in the reaction volume. After the titration the gas mixture is further diluted with zero air to achieve a $\mathrm{NO}_{\mathrm{x}}$ mixing ratio of 114 ppbv. During the measurement all gas flows are kept constant. To produce different $\mathrm{NO}_{2}$ mixing ratios the $\mathrm{O}_{3}$ concentration is adjusted through the electrical current of the UV-light source. Simultaneously to the $\mathrm{NO}_{2}$ ICAD measurements, the NO mixing ratio in the sample gas is measured by a calibrated NO Chemiluminescence Detector (Eco Systems, CLD $770 \mathrm{Al}$ ppt). This allows to calculate the exact $\mathrm{NO}_{2}$ mixing ratio from the comparison with a measurement at deactivated ozone generator as the total $\mathrm{NO}_{\mathrm{x}}$ mixing ratio is constant $\left(X_{\mathrm{NO}_{2}}=X_{\mathrm{NO}_{x}}-X_{\mathrm{NO}}\right)$. 


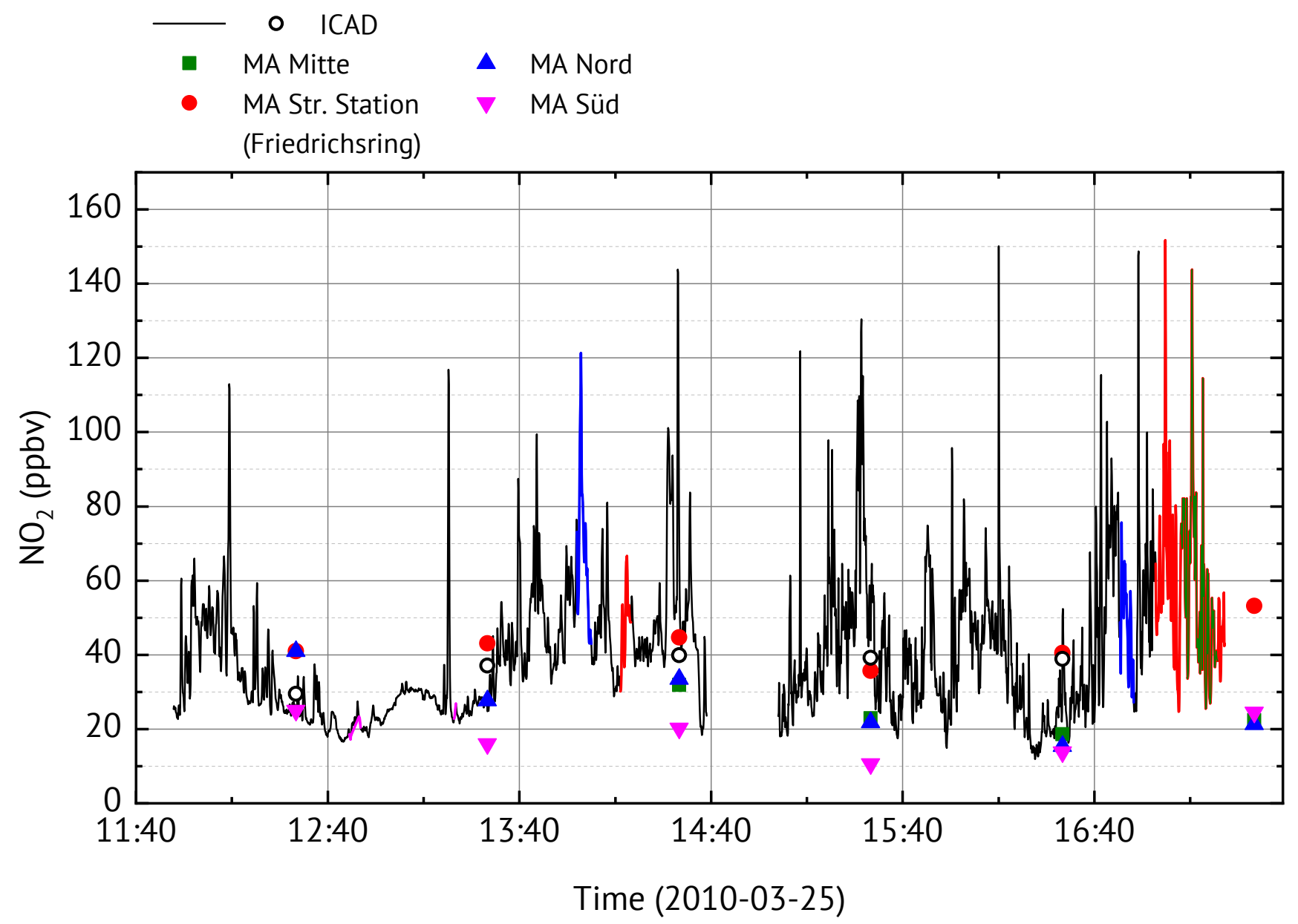

Figure S2. $\mathrm{NO}_{2}$ time series for the automobile measurements (instrument configuration 1). The line graph shows the ICAD measurements at full time resolution. Additionally the hourly averages from the ICAD and four air quality stations are shown for comparison. The line graph has the colour of an air quality station at time intervals where the car is closer than $1.5 \mathrm{~km}$ to the station. 